\title{
Cholera El Tor in Calcutta
}

\author{
S. MUKERJEE,* M.B., D.PHIL.
}

Cholera El Tor, which had been confined for several decades to its original home in the Celebes islands, began to spread out in a pandemic form in 1961. By 1963 most of the islands in the Western Pacific were involved in the pandemic, as were also many countries in South and South-east Asia. By the end of 1963 cholera El Tor had penetrated into East Pakistan, and from April 1964 it has also been present in Calcutta. Thus the Indo-Pakistan subcontinent is now having for the first time a mixed infection of classical cholera and cholera $\mathrm{El} \mathrm{Tor.} \mathrm{In}$ this paper some bacteriological, epidemiological, and immunological problems arising from this situation are discussed.

\section{Materials and Methods}

Strains of El Tor Vibrios.-In all 35 strains of Vibrio el tor isolated from patients admitted in the Infectious Diseases Hospital, Calcutta, and Satya Bala Debi Hospital, Howrah, were available for bacteriological tests. Twenty-three strains were obtained by courtesy of Dr. D. L. Shrivastava, of the Cholera Research Centre, Calcutta. Five strains were kindly forwarded by Dr. D. Barua, of the School of Tropical Medicine, Calcutta, and seven strains were isolated in our laboratory. The strains were derived from patients residing at widely separated areas in Calcutta and Howrah.

Haemolysis Test.-To a 24-hour culture of the vibrio strain in nutrient broth at $\mathrm{pH} 7.4$ was added an equal volume of $1 \%$ sheep erythrocyte suspension. Readings were taken after two hours' incubation at $37^{\circ} \mathrm{C}$. and then overnight in the refrigerator

Haemagglutination Test.-This was done according to the method described by Finkelstein and Mukerjee (1963).

Tests of Susceptibility to Cholera Typing Phages.-The test was carried out with the four groups of cholera typing phages as described earlier (Mukerjee et al., 1957). In our earlier studies the group IV cholera phages were found to have no lytic affinity for El Tor strains. However, further observations with larger series of strains have shown that when used undiluted this phage may lyse some of the $V$. el tor strains to varying degrees; but at the critical test-dilution for Vibrio cholerac, strains of El Tor vibrios are universally resistant to lysis by it. For differentiation between the two O-group I vibrios all the four cholera typing phages were used at the critical test dilutions for $V$. cholerae. Besides the group IV phages, group II phages are also not lytic for any of the $V$. el tor strains.

Polymyxin Sensitivity Test.-This test was carried out according to the method of Gan and Tija (1963), using " bactosensitivity" disks (Difco Laboratories) containing 50 units of polymyxin B per disk.

Soda-serum-agglutination Test.-The technique described by Tanamal (1959) was used.

El Tor Phage-typing.-This was carried out according to our tentative scheme (Mukerjee, 1964a) with the help of five phages isolated from lysogenic strains of $V$. el tor.

- Director, W.H.O. International Reference Centre for Vibrio Phage Typing, Indian Institute for Biochemistry and Experimental Medicine, Calcutta-32, India.
Lysogenicity Test.-A 24-hour broth culture of the test strain was treated with $0.06 \%$ toluene for one hour. The toluene was removed by evaporation in a vacuum desiccator for about one hour. The broth was then tested for phage by spotting on the lawn of a universally susceptible $V$. el tor strain. Strain No. Makassar 757 (non-haemolytic), obtained by courtesy of Dr. P. Nicolle, of the Pasteur Institute, Paris, was generally used as the indicator and propagating strain. In case the lysogenic phages were not detectable by spot tests, they were plated with the susceptible indicator strain by the agar-layer method either directly or after two or three blind passages with the susceptible propagating strain.

Pathogenicity Tests.-The pathogenicity of the El Tor strains was tested in ligated loops of the small intestine of adult rabbits according to the method of De and Chatterjee (1953), and lethality to infant rabbits was tested by intra-intestinal administration of young cultures of vibrios (Dutta and Habbu, 1955).

\section{Results}

The results of tests for bacteriological characterization of the strains are given in the accompanying Table. All strains belonged to Heiberg group I by sugar-fermentation tests and

Results of Tests Used for Identification of the 35 Strains as El Tor

\begin{tabular}{|c|c|c|c|}
\hline $\begin{array}{l}\text { Serial } \\
\text { No. of } \\
\text { Test }\end{array}$ & Test & $\begin{array}{c}\text { Number of } \\
\text { Strains Showing } \\
\text { Positive } \\
\text { Reactions }\end{array}$ & $\begin{array}{c}\text { Number of } \\
\text { Strains Showing } \\
\text { Negative } \\
\text { Reactions }\end{array}$ \\
\hline $\begin{array}{l}1 \\
2 \\
3 \\
4 \\
5\end{array}$ & $\begin{array}{l}\text { Haemolysis } \\
\text { Haemagglutination } \\
\text { Polymyxin B sensitivity } \\
\text { Soda-serum-agglutination } \\
\text { Lysis by cholera phage be- } \\
\text { longing to } \\
\text { group I } \\
\text { group II } \\
\text { group III } \\
\text { group IV } \\
\text { Lysogenicity for } V \text {. el tor } \\
\text { indicator strain }\end{array}$ & $\begin{array}{r}17 \\
35 \\
0 \\
32 \\
\\
6 \\
0 \\
32 \\
0 \\
14\end{array}$ & $\begin{array}{r}18 \\
0 \\
35 \\
3 \\
\\
29 \\
35 \\
3 \\
35 \\
21\end{array}$ \\
\hline
\end{tabular}

In accordance with the tentative El Tor phage-typing scheme 23 of the strain were found to belong to type 4,8 to type 5,1 each to types 1 and 3 , and 2 were untypable.

were agglutinable by cholera $\mathrm{O}$ and Ogawa $\mathrm{O}$ monospecific sera. Five strains were also agglutinable to varying titres with a monospecific Inaba $\mathrm{O}$ serum. None agglutinated with the rough $\mathrm{O}$ serum.

Five representative strains were tested for pathogenicity to laboratory animals. All of them gave rise to the typical gutinflammatory reaction in the ligated intestinal loops of rabbits. Two of them were also tested for lethality to infant rabbits. Both strains gave positive reactions. In conformity with earlier findings (Mukerjee, 1963b) the infant rabbits did not develop diarrhoea, but on post-mortem examination showed distension of the large intestine with fluid. Control tests with known pathogenic El Tor strains showed the same type of reactions, while apathogenic Middle East and water strains reacted negatively.

\section{Discussion}

It may be secn from the Table that 17 of the strains were non-haemolytic when first tested but all strains were haem- 
agglutinating, polymyxin B-insensitive, and non-susceptible to groups II and IV cholera phages. They gave a positive sodaserum-agglutination test. All these tests characterized the strains as $\mathrm{El}$ Tor vibrios.

It is now agreed by cholera workers that haemolysis is not a stable character of El Tor vibrios. It has been reported (Roy, Mukerjee, and Tanamal, 1963) that, out of $663 \mathrm{~V}$. el tor strains isolated in different outbreaks of the present $\mathrm{El}$ Tor pandemic, 162 (approximately $25 \%$ ) of the strains were found to be nonhaemolytic. The majority of the originally non-haemolytic strains, however, yielded haemolytic colonies on blood-agar plates and the rest of the cultures acquired a haemolytic character after repeated propagation in the laboratory. The haemolytic patterns of the Calcutta El Tor strains were of the same order as those from other areas involved recently in the pandemic. All strains of the New Guinea outbreaks and an occasional strain from another area, however, proved to be stably non-haemolytic.

It would be evident from the above results that no reliance can be placed on the haemolysis test for differentiating $V$. cholerae and $V$. el tor. Failure to recognize this resulted in errors in bacteriological characterization of the cholera El Tor outbreaks in the first year of the present pandemic (Mukerjee and Guha Roy, 1962). There has also been some confusion in later years. Some workers believed that the disease in Thailand and Malaya might have been of mixed cholera and $\mathrm{El}$ Tor types, while the epidemic in Burma was thought in the beginning to be of the classical type. But examination of large series of vibrio strains from each of these areas in our laboratories and elsewhere, including those of Drs. C. E. de Moor, H. Noyece, and H. B. Maitland, has proved beyond doubt that they belong exclusively to the El Tor type.

\section{Testing of Strains}

So far, susceptibility to lysis by the group IV cholera phages has been proved to yield the most consistent results, but the test requires the facilities of a comparatively specialized laboratory. Haemagglutination, polymyxin-B-sensitivity, and soda-serum-agglutination tests are also reliable. And although exceptions to the expected results are observed from time to time with each of these tests, they can be carried out conveniently in all laboratories. For obtaining dependable results these tests should preferably be used in combination. The results of all tests have confirmed the Calcutta strains to belong to the El Tor type.

The strains were also tested with the five El Tor phages of the tentative phage-typing scheme developed for El Tor vibrios. A vast majority of the strains belonged to phage-types 4 and 5 . It has already been reported (Mukerjee, 1964a) that marked dissociation in phage-types may be observed in colonies of El Tor strains derived from a single culture. Therefore, as most of the strains in the present work were derived by selections from single colonies, variations in the phage-types of strains of this epidemic may not be considered an unexpected finding. As a matter of fact, most of the outbreaks of cholera El Tor in the present pandemic have yielded more than one phage-type of strains.

When tested with an $\mathrm{El}$ Tor indicator strain 14 of the strains proved to be lysogenic. The lysogenic phages of these strains were found to belong to the same antigenic groups as those isolated from case strains of $\mathrm{El}$ Tor vibrios from other outbreaks in the present pandemic. It may be pointed out that Takeya and Shimodori (1963) reported that in their series all strains of $V$. el tor isolated from patients were found to be lysogenic, while the non-pathogenic $\mathrm{El}$ Tor vibrios from the Middle East, Calcutta water sources, and Ubol in Thailand were non-lysogenic. This led them to suggest that in El Tor strains lysogenicity is probably associated with virulence. Their observations are not, however, confirmed by our studies or by those of Dr. C. E. de Moor (personal communication). We have both found that a number of strains isolated from patients are non-lysogenic, while a proportion of the Middle East strains, as well as the $\mathrm{El}$ Tor strains isolated in 1957 from Calcutta water sources in the absence of $\mathrm{El}$ Tor diseases in the area, are lysogenic.

The results of pathogenicity tests in the ligated intestinal loops of rabbits as well as infant rabbits showed that the 1964 $V$. el tor strains isolated from patients in Calcutta belonged to the pathogenic type, as distinct from the apathogenic El Tor vibrios isolated in 1957 from water sources in Calcutta in the absence of cholera El Tor. This proves that the present El Tor epidemic in Calcutta is not sui generis but an infection imported from outside in the course of spread of the present pandemic.

\section{Spread of Phage-types}

Studies of El Tor strains isolated in different areas involved in the pandemic by a tentative phage-typing scheme (Mukeriee, 1964a) has yielded evidence to show that the phage-types of strains of $V$.el tor in one country often differ from those found in neighbouring countries. This indicates that El Tor infection did not necessarily spread across a widening front from one territory to adjacent areas, but rather the causative vibrios were independently carried to several countries direct from Indonesia. This has been confirmed by observation in the recent cholera El Tor infections in Burma (Mukerjee, 1964b).

The line of spread of cholera El Tor to Calcutta still remains to be established. It is easy to assume that the large-scale influx of refugees from East Pakistan to Calcutta, which started in the beginning of 1964, might have played some part in the spread of this epidemic. The possibility of exchange of cholera infections between West Bengal and East Pakistan has been established by phage-typing of $V$. cholerae strains isolated from either side of the Indo-Pakistan border (Mukerjee et al., 1963). Cholera El Tor is known to have been present in East Pakistan towards the end of 1963. But outbreaks of El Tor infections there appear to have remained limited in an area around Chittagong, although it is possible that it had spread to remote areas where facilities for bacteriological examination had not been organized. In the absence of confirmed cases in East Pakistan outside the Chittagong area, the possibility cannot be excluded that El Tor infection may have spread to India by an alternative route such as by the sea route from countries like Burma and Thailand.*

At the time of writing (middle of May 1964) cases of cholera El Tor are already distributed over scattered areas in Calcutta and have also spread to Howrah, which is situated on the other bank of the River Hooghly. The symptoms in patients are usually mild and therefore likely to be overlooked as cases of diarrhoea. These atypical cases are therefore more dangerous potentially in spreading infections than frank cases of clinical cholera. Further, it may be remembered that, in contrast to classical cholera, the carrier state in cholera El Tor may be prolonged and a number of healthy carriers may exist in a locality before, during, and after an outbreak. The role of such carriers in spreading the infection remains to be ascertained.

\section{Plea for Mass Prophylaxis}

So far the problem of cholera El Tor was only of academic interest to India. However, toward the end of 1963, when the causative vibrios of the Burmese outbreaks were identified as El Tor vibrios, the possibility of cholera El Tor spreading to

' Since submitting this paper 18 strains of El Tor vibrios from East' Pakistan have been tested. They were found to belong to a phagetype different from those of the Calcutta strains. 
the Indo-Pakistan subcontinent appeared to be imminent (Mukerjee, 1964b). I have pleaded for the proper characterization of vibrio strains in all fresh epidemics and recommended that in case El Tor infection spread to Indian soil, all-out measures must be adopted to contain infections locally.

In the developing countries with inadequate funds and equipment to implement the necessary sanitary measures, prophylactic immunization of the susceptible population still forms one of the most important measures of epidemic control. And although the prophylactic value of the killed cholera vaccine remains to be determined in properly planned double-controlled field trials, cholera vaccine has generally been accepted as a valuable means of individual and mass prophylaxis. The question of prophylactic immunization against cholera in India now needs further careful consideration.

El Tor vibrios possess identical heat-stable specific lipopolysaccharide antigen with $V$. cholerae. Cross-protection against the heterologous type is known to exist in animals immunized with either type (Pittman and Feely, 1963 ; Vella, 1963; Watanabe and Verway, 1962). Pittman and Feely inferred from the results of the mouse-protection test that immunization with classical cholera vaccine should afford protection against human infection by both the vibrios. However, the two vibrios differ in respect of other cellular constituents, like protein and also of the toxins. Further, it has been pointed out (Mukerjee, 1963a) that human cholera differs widely from the mouse infection by intraperitoneal challenge with a heavy dose of live cultures of vibrios, and additional antigen-antibody systems may be involved in human infections. In a few epidemiological observations on cholera $\mathrm{El}$ Tor, claims for the protective values of classical cholera vaccine could not be substantiated. De-Moor (1963) reported that the campaign of classical cholera vaccination proved a failure in the Philippines. In the Burmese epidemics of cholera El Tor in 1963 numerous cases of cholera were recorded among persons inoculated with classical cholera vaccine. Out of 387 cholera patients admitted in the contagious-disease hospital in Rangoon $83 \%$ cases gave a history of recent cholera inoculations and $69 \%$ of them were reported to have been inoculated more than 10 days and less than 85 days before they developed cholera. Many workers with wide experiences of cholera $\mathrm{El}$ Tor epidemics (including Dr. C. E. de Moor, Dr. O. Felsenfeld, Mr. S. J. W. Tanamal, and Dr. R. A. Finkelstein, personal communications) recommend that $\mathrm{El}$ Tor vaccine should be used against El Tor infections. El Tor vaccines are now being increasingly employed for prophylaxis in many of the areas infected with El Tor vibrio. Recently Basaca-Sevilla, Pesigan, and Finkelstein (1964) reported that in comparison with $V$. cholerae vaccine, vaccine prepared from $\mathrm{El}$ Tor vibrios was more antigenic in humans and more potent in protecting mice against challenge by both $V$. cholerae and $V$. el tor. In view of the emergence of mixed infections of classical and El Tor cholera in the Indo-Pakistan subcontinent, it may therefore be thought appropriate that the standard anti-cholera vaccines here should consist of both $V$. cholerae and $V$. el tor antigens. Such a vaccine was recommended (Mukerjee, 1964b) as one of the measures to be adopted for preventing $\mathrm{El}$ Tor infections from gaining a foothold in India. It was also suggested that a mixed cholera-El Tor vaccine may be included as one of the vaccines to be subjected to the comparative evaluation in the pending field trials of cholera vaccine in Calcutta. This idea was also in conformity with a suggestion by Vella (1963). However, such a trial could not be undertaken at present for administrative and other considerations. It is to be hoped that it will be taken up in the future after the first objective of assessing the value of the cholera vaccine against classical cholera is ascertained. For the sake of uniformity and convenience of administrative control, $V$. cholerae and $V$. el tor infections are regarded as one disease-cholera. It is therefore logical to hope that one type of cholera vaccine also would be used internationally, provided it can be proved to have immunizing potency against infections by both types of vibrio. But, pending such a vaccine being accepted, there is sufficient justification for using the mixed vaccine in places where infections due to both the vibrios exist or are likely to spread, while for other areas vaccines may be prepared of the prevailing type of the infecting vibrio.

\section{Summary}

By April 1964 the pandemic spread of cholera El Tor had reached Calcutta. It soon became distributed over scattered areas in the city and also in Howrah, which is situated on the other bank of the River Hooghly. So far the infection does not appear to have spread to other cholera-endemic areas in India.

Nearly $50 \%$ of the strains of $\mathrm{El}$ Tor vibrios isolated in Calcutta appeared to be non-haemolytic when first tested. But all strains were haemagglutinating, insensitive to the group IV cholera typing phage and polymyxin B, and all but three strains gave positive soda-serum-agglutination test. Only 14 of the strains were lysogenic. They appeared to be of the pathogenic type, giving rise to gut-inflammatory reaction in adult rabbits and death in infant rabbits. These strains thus differed from the apathogenic $V$. el tor strains isolated in 1957 from Calcutta water sources. Therefore the epidemic is not sui generis, but imported.

The source of origin of this infection remains undetermined. The nearest focus of cholera $\mathrm{El}$ Tor connected by direct land route is in East Pakistan. But although El Tor infection had spread there in 1963, it still appears to be restricted to a limited area in and around Chittagong. The other possible lines of spread are by the direct sea route from other El-Tor-infected countries like Burma and Thailand.

The question of prophylactic immunization against cholera now needs careful consideration. Pending further researches, one may be justified in proposing that a mixed cholera-El Tor vaccine should be used in places where mixed infections of classical and $\mathrm{El}$ Tor cholera exist or are likely to spread, while for other areas vaccines prepared with the prevailing type of vibrio may be employed.

I am grateful to Dr. D. Barua, Professor of Bacteriology, School of Tropical Medicine, Calcutta, and Dr. D. L. Shrivastava, of the Cholera Research Centre, Calcutta, for kindly forwarding the El Tor strains isolated in their laboratories. Thanks are also due to Drs. U. K. Guha Roy and B. C. Rudra for their assistance in isolating the El Tor strains and to Mr. K. N. Maitra, Mr. I. Guha Thakurta, and Mr. M. L. Chowdhury for their technical assistance. I am indebted to Dr. A. Narayanaswami for his helpful suggestions.

\section{REFERENCES}

Basaca-Sevilla, V., Pesigan, T. P., and Finkelstein, R. A. (1964). Amer. f. trop. Med. Hyg., 13, 100.

De, S. N., and Chatter,ee, D. N. (1953). F. Path. Bact., 66, 559.

De Moor, C. E. (1963). Trop. geogr. Med., 15, 97

Dutta, N. K., and Habbu, M. K. (1955). Brit. F. Pharmacol., 10, 153

Finkelstein, R. A., and Mukerjee, S. (1963). Proc. Soc. exp. Biol. (N.Y.), 112, 355 .

Gan, K. H., and Tiia, S. K. (1963). Amer. F. Hyg 77,184

Mukeriee, S. (1963a). Amer. F. Trop. Med. Hyg., 12, 388. Mukeriee, S. (1963a). Amer. F. Trop. Med. Hy (1963b). Bull. Wld Hlth Org., 29, 753.

(1964b). Paper pres 1903. in press. Guha, D. K., and Guha Roy, U. K. (1957). Ann. Biochem. 17, 161.

- and Guha Roy, U. K. (1962). Brit. med. f., 1, 685.

- and Rudra, B. C. (1963). Ann. Biochem., 23, 523.

Pitman, M., and Feeley, J. C. (1963). Bull. Wtd Hlth Org., 28, 379 Roy, Chitra, Mukerjee, S., and Tanamal, S. J. W. (1963). Ann. Biochem.,

Takeya, K., and Shimodori, S. (1963). F. Bact., 85, 957

Tanamal, S. T. W. (1959). Amer. f. trop. Med. Hyg., 8, 72.

Vella, E. E. (1963). Brit. med. F., 1, 1203.

Watanabe, Y., and Verway, W. F.' (1962). Bact. Proc., p. 89. 